\title{
Association of progranulin and high sensitivity CRP concentrations in gingival crevicular fluid and serum in chronic periodontitis subjects with and without obesity
}

\author{
AR Pradeep*, N Priyanka, MVR Prasad, Nitish Kalra and Minal Kumari \\ Department of Periodontics, Government Dental College and Research Institute, Bangalore, Karnataka, India
}

\begin{abstract}
Background: Obesity is considered as a strong risk factor of inflammatory periodontal tissue destruction. The purpose of this study is to determine presence of progranulin (PGRN) and high sensitivity C reactive protein (hs CRP) levels in serum and gingival crevicular fluid (GCF) in obese subjects with chronic periodontitis and to find an association, if any.

Material and methods: 40 subjects (20 males and 20 females) were selected based on their clinical parameters into four groups (10 subjects in each group): group 1 (healthy non obese), group 2 (healthy obese), group 3 (non obese with chronic periodontitis) and group 4 (obese with chronic periodontitis). Serum and GCF PGRN levels were estimated by enzyme linked immunosorbant assay (ELISA) and hs CRP levels were estimated by immunoturbidimetry method.

Results: The mean PGRN and hs CRP concentration both in serum and GCF were highest for group 4 followed by group 3, group 2 and least in Group 1.

Conclusion: PGRN and hs CRP may be novel biomarkers of the chronic inflammatory response in obesity and chronic periodontitis.
\end{abstract}

Keywords: Chronic periodontitis, $\mathrm{C}$ reactive protein, progranulin, obesity

\section{Introduction}

Chronic periodontitis (CP) involves the destruction of the supporting structures of the teeth including the periodontal ligament, bone and gingival tissues [1]. $\mathrm{CP}$ is considered to have multiple risk factors. The presence of microorganisms is a crucial factor in inflammatory periodontal disease, but the progression of the disease is related to host-based risk factors. Other risk factors including plaque or oral hygiene mod-

${ }^{*}$ Corresponding author: AR Pradeep, Department of Periodontics, Government Dental College and Research Institute, Bangalore560002, Karnataka, India. Fax: +918 26703176; E-mail: periodonticsgdcri@gmail.com. ifications, systemic health including diabetes and human immuno deficiency virus, socio-economics, stress, obesity, smoking, genetics, age, gender, are all relevant and may interact to render subjects at increased risk.

Obesity is characterized by the abnormal or excessive deposition of fat in the adipose tissue. It is a major public health problem today. The prevalence of obesity has increased substantially over the past decades in most industrialized countries [2]. Obesity is a risk factor for several chronic diseases, most notably hypertension, type 2 diabetes, dyslipidemia, and coronary heart disease [3]. Excess bodyweight is now the sixth most important risk factor contributing to the overall burden of disease worldwide [4]. It also has negative effects in relation to $\mathrm{CP}$, because of the increase in proinflammatory cytokines. Recent studies have suggested that obe- 
sity is associated with oral diseases, particularly CP [57]. It has been suggested that obesity is second only to smoking as the strongest risk factor for inflammatory periodontal tissue destruction [8]. The adipose tissue actively secretes a variety of cytokines and hormones that are involved in inflammatory processes, pointing towards similar pathways involved in the pathophysiology of obesity, CP and related inflammatory diseases.

Progranulin (PGRN), also called as granulin/epithelin precursor, proepithelin, PC cells-derived growth factor and acrogranin, is a glycosylated protein released by a variety of cells [9]. PGRN is a 593-amino acid, cysteine-rich protein with an estimated molecular weight of $68.5 \mathrm{kDa}$ that runs at $90 \mathrm{kDa}$ on standard western blots due to heavy glycosylation [10]. Proteolytic cleavage of the precursor protein by extracellular proteases, such as elastase, gives rise to smaller peptide fragments termed granulins (GRNs) or epithelins [11]. These fragments range in size from 6 to $25 \mathrm{kDa}$ and have been implicated in a range of biological functions $[11,12]$. Mutations in PGRN cause frontotemporal lobar degeneration with ubiquitin-immunoreactive neuronal inclusions (FTLD-U) [13]. PGRN mRNA has been demonstrated in various tissues and organs including the reproductive organs, gastrointestinal tract, endocrinal organs, and neural tissues $[14,15]$. It is particularly prominent in epithelial and hematopoietic cells, and tends to be more highly expressed in tissues with high turnover rates such as gastric mucosa, lymphoid tissue, and tumor cell lines [15,16].

PGRN has been also implicated in wound healing and inflammation [17-19]. During the wound repair response, PGRN is upregulated and stimulates neutrophil and macrophage infiltration and neovascularization of wound tissue [18]. Circulating PGRN significantly correlates with body mass index (BMI), macrophage infiltration in omental adipose tissue, high sensitivity Creactive protein (hs-CRP) serum concentrations, A1C values, and total cholesterol. Multivariable linear regression analyses revealed CRP levels as the strongest independent predictor of circulating PGRN [20].

CRP is a well-known acute-phase reactant produced by the liver in response to inflammation due to various stimuli [21]. Various studies have shown that serum CRP levels were elevated in obesity [22, 23] and periodontal disease [24,25]. Studies [26,27] have shown an association between obesity and periodontitis, which is mediated by cytokine production. Hence, increased amount of adipose tissue could contribute to altered gingival crevicular fluid (GCF) and serum profiles of inflammatory markers.
A study suggests a close coregulation between CRP and PGRN serum concentration and demonstrates that PGRN may be a novel biomarker of the chronic inflammatory response in central obesity and associated disturbances [20]. Hence, PGRN is an important molecule in inflammatory response. We hypothesize that these molecules may be involved in chronic subclinical inflammation associated with human obesity and CP. Till date, PGRN and hs-CRP concentrations in serum and GCF in obese subjects with $\mathrm{CP}$ has not been explored. Hence, the aim of the present study is to assess the concentration of PGRN and hsCRP in serum and GCF of obese subjects with CP to find their association, if any.

\section{Material and methods}

The study was carried out from June 2011 to September 2011. The study group consisted of 40, age and gender balanced subjects (25-45 years; gender: 20 males and 20 females) attending the outpatient section, Department of Periodontics, Government Dental College and Research Institute, Bangalore. Written informed consent was obtained from those who agreed to participate voluntarily. The Ethical Clearance was approved by Institutional Ethical Committee and Review Board.

\subsection{Inclusion criteria}

Subjects in the age group of 25-45 years; presence of at least 20 natural teeth, subjects with a diagnosis of CP based on clinical parameters like probing depth (PD), clinical attachment level (CAL) [28], gingival index (GI) [29]; subjects having BMI, in non obese subjects in the range of $18.522 .9 \mathrm{~kg} / \mathrm{m}^{2}$ and in obese subjects $\geqslant 25 \mathrm{~kg} / \mathrm{m}^{2}$ and waist circumference $(\mathrm{WC}) \geqslant 90 \mathrm{~cm}$ in men and $\geqslant 80 \mathrm{~cm}$ in women [30], were selected in this study. Radiographic bone loss was recorded dichotomously (presence or absence) to differentiate subjects with CP from other groups.

\subsection{Exclusion criteria}

Subjects with aggressive periodontitis, hypertension, a smoking habit, type 2 diabetes, gross oral pathology, heart diseases, rheumatoid arthritis, osteoarthritis, dyslipidemia, tumors, or any other systemic disease that can alter the course of periodontal disease, or those who had any course of medication affecting periodontal status or had received periodontal therapy in the preced- 
ing 6 months were excluded from the study. Subjects with other acute or chronic medical conditions or infectious diseases like pneumonia and other febrile illnesses or inflammatory states that could have an impact on the levels of these inflammatory mediators were also excluded.

\subsection{Grouping criteria}

The subjects were categorized into 4 groups based on GI, PD, CAL, BMI, and WC. Group 1 (healthy non obese) consisted of 10 subjects with clinically healthy periodontium with no evidence of disease. The score obtained after assessing the gingival status using GI was zero, $\mathrm{PD} \leqslant 3 \mathrm{~mm}$ and $\mathrm{CAL}=0$ with no crestal bone loss as determined from radiograph and the BMI value more than $18.5 \mathrm{~kg} / \mathrm{m}^{2}$ and less than $22.9 \mathrm{~kg} / \mathrm{m}^{2}$ and $\mathrm{WC}<90 \mathrm{~cm}$ in men and $<80 \mathrm{~cm}$ in women. Group 2 (healthy obese) consisted of 10 subjects with clinically healthy periodontium with no evidence of disease. The score obtained after assessing the gingival status using GI was zero, $\mathrm{PD} \leqslant 3 \mathrm{~mm}$ and $\mathrm{CAL}=0$ with no crestal bone loss as determined from radiograph and the BMI value more than $18.5 \mathrm{~kg} / \mathrm{m}^{2}$ and $\mathrm{WC} \geqslant$ $90 \mathrm{~cm}$ in men and $\geqslant 80 \mathrm{~cm}$ in women. Group 3 (non obese with $\mathrm{CP}$ ) consisted of 10 subjects, who showed clinical signs of gingival inflammation, $P D \geqslant 5 \mathrm{~mm}$ and attachment loss i.e. CAL $\geqslant 3 \mathrm{~mm}$ with radiographic evidence of bone loss. The GI score 1 was obtained for these subjects and the BMI value more than $18.5 \mathrm{~kg} / \mathrm{m}^{2}$ and less than $25 \mathrm{~kg} / \mathrm{m}^{2}$ and $\mathrm{WC}<90 \mathrm{~cm}$ in men and $<$ $80 \mathrm{~cm}$ in women. Group 4 (obese with CP) consisted of 10 subjects, who showed clinical signs of gingival inflammation, $\mathrm{PD} \geqslant 5 \mathrm{~mm}$ and attachment loss i.e. $\mathrm{CAL} \geqslant 3 \mathrm{~mm}$ with radiographic evidence of bone loss. The GI score $>1$ was obtained for these subjects and the BMI value more than $25 \mathrm{~kg} / \mathrm{m}^{2}$ and $\mathrm{WC} \geqslant 90 \mathrm{~cm}$ in men and $\geqslant 80 \mathrm{~cm}$ in women.

\subsection{Clinical evaluation of subjects}

Group allocations and sample site selections were performed by the chief coordinator (ARP). A calibrated examiner (PN) did the clinical evaluation measuring the clinical parameters including PD, CAL, GI using a University of North Carolina-15 periodontal probe. ${ }^{1}$ The same examiner (PN) also did the radiographic evaluation and collected the GCF samples.

\footnotetext{
${ }^{1} \mathrm{Hu}$-friedy, Chicago, IL, USA.
}

\subsection{Site selection and GCF collection}

Two test sites for GCF sample collection were selected based on the highest scored sites in the oral cavity. In group 3 and group 4 subjects, the 2 sites showing the greatest CAL and signs of inflammation, along with radiographic confirmation of bone loss, were selected for sampling. One of the 2 sites selected/subject was used for hs-CRP while the other for PGRN analysis. In the healthy group, to standardize site selection and obtain adequate fluid volume, sampling was predetermined to be from the mesio-buccal region of the maxillary right first molar, in the absence of which the left first molar was sampled. First, the selected site was cleaned, isolated and air dried using sterile cotton rolls and the supragingival plaque was removed gently using a Universal gracey curette \#4R/4L $\mathrm{L}^{2}$ to avoid contamination of the paper strips. The paper strips ${ }^{3}$ were placed gently at the entrance of the gingival sulcus/ crevice until the light resistance was felt [31], care being taken to avoid mechanical injury, and left in place for 60 seconds. The absorbed GCF volume of each strip was determined by electronic impedance. ${ }^{4}$ Samples that were suspected to be contaminated with blood and saliva were excluded from the study. After collection of the gingival fluid, the two periopaper strips/site that absorbed GCF from each subject were pooled and were immediately transferred in microcentrifuge tubes (premarked with the biomarker name) containing $400 \mu \mathrm{l}$ of phosphate buffer saline and stored frozen at $-70^{\circ} \mathrm{C}$ for subsequent analysis. Periodontal treatment (scaling and root planing) was performed for $\mathrm{CP}$ subjects at the same appointment after GCF collection by the operator (NK).

\subsection{Blood collection}

Two milliliters of blood was collected from the antecubital fossa by venipuncture using a 20 -gauge needle with 2-ml syringe and immediately transferred to the laboratory. The blood sample was allowed to clot at room temperature and, after 1 hour serum was separated from blood by centrifuging at $3000 \mathrm{~g}$ for $5 \mathrm{~min}$. The serum was immediately transferred to a plastic vial and stored at $-70^{\circ} \mathrm{C}$ until the time of assay.

\footnotetext{
${ }^{2}$ Hu-friedy, Chicago, IL, USA.

${ }^{3}$ Periopaper, Ora Flow Inc., Amityville, NY, USA.

${ }^{4}$ Periotron 8000, ProFlow Inc., Amityville, NY, USA.
} 
Table 1

Descriptive statistics of study population (mean \pm S.D.)

\begin{tabular}{lcccc}
\hline Study group & Group 1 $(n=10)$ & Group 2 $(n=10)$ & Group 3 $(n=10)$ & Group 4 $(n=10)$ \\
\hline Age (in years) & $32.42 \pm 3.20$ & $35.20 \pm 3.54$ & $35.22 \pm 3.11$ & $36.87 \pm 3.32$ \\
Sex (M/F) & $6 / 4$ & $5 / 5$ & $4 / 6$ & $5 / 5$ \\
BMI & $20.84 \pm 2.55$ & $28.16 \pm 2.22$ & $20.63 \pm 2.58$ & $31.95 \pm 2.71$ \\
GI & - & - & $2.21 \pm 0.54$ & $2.15 \pm 0.51$ \\
PD & $2.21 \pm 0.22$ & $2.12 \pm 0.12$ & $8.01 \pm 1.29$ & $7.32 \pm 1.88$ \\
CAL & $2.12 \pm 0.45$ & $1.91 \pm 0.33$ & $6.22 \pm 1.12$ & $5.61 \pm 1.56$ \\
Serum PGRN (ng/ml) & $78.2 \pm 2.22$ & $205.9 \pm 2.88$ & $182.2 \pm 2.37$ & $237.6 \pm 2.74$ \\
GCF PGRN (ng/ml) & $71.8 \pm 2.54$ & $197.8 \pm 3.22$ & $176.7 \pm 2.45$ & $231.5 \pm 3.11$ \\
Serum hs-CRP (mg/l) & $1.7 \pm 0.32$ & $4.03 \pm 0.51$ & $3.89 \pm 0.17$ & $6.49 \pm 0.24$ \\
GCF hs-CRP (mg/l) & $0.52 \pm 0.25$ & $1.00 \pm 0.12$ & $0.93 \pm 0.74$ & $1.14 \pm 0.32$ \\
\hline
\end{tabular}

\subsection{PGRN analysis}

The samples were assayed for PGRN using enzymelinked immunosorbent assay (ELISA) kit according to manufacturer's instructions. ${ }^{5}$ The GCF sample tubes were first homogenized for 30 seconds and centrifuged for 5 minutes at $1,500 \mathrm{~g}$ to elute. The elute was then used as sample for ELISA estimation from GCF samples. A polyclonal antibody specific for human PGRN had been pre-coated onto 96 well microplate. Standards and samples were pipetted into the wells and any PGRN present was bound by immobilized antibody. Bound progranulin was captured by biotinylated antihuman PGRN polyclonal antibody. HRP conjugated streptavidin was added. After washing, a substrate solution was added. The colors developed in proportion to the bounded PGRN quantity. Colour development was monitored using a microplate reader until an optimum optical density was reached, a stop solution was added and the optical density was read at $450 \mathrm{~nm}$. The total PGRN was determined in nanograms (ng), and the calculation of the concentration in each sample was performed by dividing the amount of PGRN by the volume of sample $(\mathrm{ng} / \mathrm{ml})$.

\section{8. hs-CRP analysis}

The samples for CRP were measured immunoturbidimetrically using RANDOX analyser. The microcentrifuge tubes containing the periopaper strips and plastic vials containing serum were transferred to the lab for immunoturbidimetric analysis. Serum was used undiluted. The measuring range of CRP is $0-220 \mathrm{mg} / \mathrm{l}$, the normal value of CRP being $<5 \mathrm{mg} / 1$ [32].

\footnotetext{
${ }^{5}$ Adipogen International Inc, Incheon, South Korea.
}

\subsection{Statistical analysis}

All data were analyzed using a software program. ${ }^{6}$ Test for the validity of normality assumption using standardized range statistics was carried out and it was found that the assumption is valid. Analysis of Variance (ANOVA) was carried out for a comparison of GCF and serum levels of PGRN and hs-CRP between the groups. Using Pearson's correlation coefficient, the relationship between PGRN and hs-CRP concentration and their relationship with clinical parameters were analyzed using a software program. p values $<0.05$ were considered statistically significant.

\section{Results}

The descriptive statistics along with the mean $\pm \mathrm{SD}$ of both serum and GCF (of all groups) are tabulated in Table 1. The mean hs-CRP and PGRN concentrations both in serum and GCF were highest for group 4 followed by group 3, group 2 and least in group 1 . To find out the equality of means between the three groups ANOVA test was carried out (Table 2). A significant difference in the serum and GCF levels of hs-CRP and PGRN was found between the 4 groups. The serum and GCF levels of PGRN were found to be significantly correlated $(p<0.05)$ to BMI and CAL in group 2 and 4 , and to PD in group 3 and 4 . The serum levels of hs-CRP were found to be significantly correlated ( $p<$ 0.05 ) to PD in group 3, and to BMI in group 2. The GCF levels of hs-CRP were found to be significantly correlated $(p<0.05)$ to PD in group 2 and to BMI in group 4 The pearson correlation coefficient test was applied to evaluate the correlation between serum levels of hs-CRP and serum levels of PGRN and also for their

\footnotetext{
${ }^{6}$ SPSS Inc. version 17.1, Chicago, IL, USA.
} 
Table 2

Results of ANOVA comparing the mean serum and GCF PGRN Conc. between four groups

\begin{tabular}{|c|c|c|c|c|c|c|c|c|}
\hline \multirow[t]{3}{*}{ Study groups } & \multicolumn{4}{|c|}{ PGRN } & \multicolumn{4}{|c|}{ hs-CRP } \\
\hline & \multicolumn{2}{|c|}{ Serum } & \multicolumn{2}{|c|}{ GCF } & \multicolumn{2}{|c|}{ Serum } & \multicolumn{2}{|c|}{$\overline{\mathrm{GCF}}$} \\
\hline & F- Value & p-value & F- Value & p-value & F- Value & p-value & F- Value & p-value \\
\hline $\begin{array}{l}\text { Group } 1 \\
\text { Group } 2 \\
\text { Group } 3 \\
\text { Group } 4\end{array}$ & 257.3 & $<0.001^{*}$ & 226.1 & $<0.001^{*}$ & 105.5 & $<0.001^{*}$ & 28.6 & $<0.001^{*}$ \\
\hline
\end{tabular}

${ }^{*}$ Significant at $\mathrm{p}$ value $<0.001$.

Table 3

Correlation of serum and GCF PGRN and hs-CRP in each group using Spearman's rank correlation coefficient test

\begin{tabular}{cccccc}
\hline Group & \multicolumn{2}{c}{ Serum } & & \multicolumn{2}{c}{ GCF } \\
\cline { 2 - 3 } \cline { 5 - 6 } & Correlation coefficient & $\mathrm{p}$ value & & Correlation coefficient & $\mathrm{p}$ value \\
\hline Group 1 & 0.35786 & 0.754 & -0.40726 & 0.074 \\
Group 2 & 0.81904 & $0.000^{*}$ & 0.36637 & 0.112 \\
Group 3 & 0.14591 & 0.539 & -0.06000 & 0.801 \\
Group 4 & -0.57987 & $0.007^{*}$ & -0.20870 & 0.377 \\
\hline
\end{tabular}

${ }^{*}$ Significant at $\mathrm{p}$ value $<0.05$.

Table 4

Relationship of PGRN to clinical parameters

\begin{tabular}{llccll}
\hline & Parameters & Group 1 & Group 2 & Group 3 & Group 4 \\
\hline Serum & GI & - & - & 0.4658 & 0.9503 \\
& PD & 0.2900 & 0.8384 & $0.0008^{*}$ & $0.0089^{*}$ \\
& CAL & 0.0572 & $0.0379^{*}$ & $0.0491^{*}$ & $0.0331^{*}$ \\
& BMI & 0.2686 & $0.0082^{*}$ & 0.0702 & $0.0015^{*}$ \\
GCF & GI & - & - & 0.4144 & 0.7796 \\
& PD & 0.2059 & 0.7591 & $0.0015^{*}$ & $0.0242^{*}$ \\
& CAL & 0.0595 & $0.0301^{*}$ & 0.0977 & $0.0494^{*}$ \\
& BMI & 0.4851 & $0.0074^{*}$ & 0.1173 & $0.0044^{*}$ \\
\hline
\end{tabular}

* Significant at $\mathrm{p}$ value $<0.05$.

GCF values. Table 3 shows the correlation coefficients and $p$ values. The correlations of the GCF and serum levels of the two biomarkers with clinical parameters are presented in Tables 4 and 5.

\section{Discussion}

Periodontal subgingival pathogens affect local and systemic immune and inflammatory response and cause the release of cytokines, this results in periodontal destruction and initiation of an acute phase systemic inflammatory response characterized by the release of CRP. This study evaluated the serum and GCF concentration of PGRN and hs-CRP that can be used as a marker of periodontal disease as well as a risk indicator for obesity [33].

Obesity has been suggested to be associated with an increased susceptibility to bacterial infection. In a study the effect of obesity on innate immune respons-
Table 5

Relationship of hs-CRP to clinical parameters

\begin{tabular}{llcccc}
\hline & Parameters & Group 1 & Group 2 & Group 3 & Group 4 \\
\hline \multirow{6}{*}{ Serum } & GI & - & - & 0.9600 & 0.9443 \\
& PD & 0.8221 & 0.9470 & $0.0378^{*}$ & 0.1286 \\
& CAL & 0.2200 & 0.3716 & 0.0978 & 0.5881 \\
& BMI & 0.4451 & $0.0119^{*}$ & 0.2003 & 0.8657 \\
GCF & GI & - & - & 0.6724 & $0.0353^{*}$ \\
& PD & 0.1559 & $0.0009^{*}$ & 0.0869 & 0.1281 \\
& CAL & $0.0000^{*}$ & 0.0737 & 0.2474 & 0.0769 \\
& BMI & 0.0891 & 0.3972 & 0.1593 & $0.0404^{*}$ \\
\hline
\end{tabular}

* Significant at $\mathrm{p}$ value $<0.05$.

es to Porphyromonas gingivalis infection, an infection strongly associated with periodontitis was investigated. Mice with diet induced obesity (DIO) and lean control C57BL/6 mice were infected orally or systemically with $P$. gingivalis, and periodontal pathology and systemic immune responses were examined postinfection. After oral infection with $P$. gingivalis, mice with DIO had a significantly higher level of alveolar bone loss than the lean controls [34].

Inflammation is thought to contribute to the development of the sequelae of obesity. Certain cytokines are thought to reduce adiponectin expression [35]. Adiponectin production is reduced with obesity. Cytokines are central to the initiation and maintenance of immune responses to periodontal bacteria. However, inappropriate cytokine secretion, whether quantitative (i.e. excessive cytokine release) and/ or qualitative (e.g. imbalance between the proportions of pro- and antiinflammatory cytokines), is a manifestation of dysregulated immune responses and leads to destruction of pe- 
riodontal tissues and the clinical signs of disease [36]. CRP plasma levels were evaluated in 174 subjects, 59 with moderate mean CAL $(2.39 \pm 0.29 \mathrm{~mm})$ and 50 with high CAL $(3.79 \pm 0.86 \mathrm{~mm})$ as compared to 65 periodontally healthy controls (CAL, $1.74 \pm 0.18 \mathrm{~mm}$ ). Statistically significant increases in CRP levels were observed in subjects with periodontal disease when compared to healthy controls [24].

In a study, multivariate linear regression showed that CRP levels were increased in subjects with generalized periodontitis and localized periodontitis compared with the controls, adjusted for age, BMI and smoking. Presence of $P$. gingivalis was also independently associated with elevated CRP levels. The authors concluded that periodontitis and subgingival $P$. gingivalis are associated with increased CRP levels thus suggesting that periodontal infection may contribute to systemic inflammatory burden in otherwise healthy individuals [37].

PGRN is a multifunctional protein that has gained attention in the neuroscience field, because of the discovery that frontotemporal dementia is associated with PGRN mutations in some subjects [13]. The physiological function of PGRN is complex, with the fulllength form of the protein having trophic and antiinflammatory activity, whereas proteolytic cleavage generates granulin peptides that promote inflammatory activity [38]. In the periphery, PGRN promotes wound healing by increasing the accumulation of neutrophils, macrophages, and other cells in wounds [18]. PGRN plays a role in the association between obesity, type 2 diabetes, and inflammatory response and in macrophage accumulation into adipose tissue in subjects with obesity [20].

ELISA estimation of serum and GCF PGRN levels were done and hs CRP concentrations were estimated by immunoturbidimetry method. PGRN and hsCRP serum and GCF concentrations are not different in men and women and do not seem to be age dependent. PGRN and hs CRP levels correlate with BMI, $\mathrm{PD}$, and CAL. The results of the present study indicated that concentrations of PGRN and hs CRP in serum and GCF increased progressively from healthy to periodontitis sites, while in periodontitis sites in obese subjects the mean concentration of PGRN was higher than the concentrations obtained in group 1, 2 and 3, suggesting that these markers reflect chronic inflammation as the periodontal disease advances from health to $\mathrm{CP}$ and their levels are much higher in CP subjects with obesity. The results of the present study are in accordance with that of previous study in which elevated serum PGRN levels in obese subjects were reported [20]. The increase in serum and GCF concentrations of hs-CRP in the present study are in accordance with a previous study [39]. In contrast to a previous study [40] which demonstrated almost non detectable amount of hs-CRP in GCF, we detected sufficiently large amount in GCF. This could be explained on the basis of two recent studies that reported local production of CRP in gingival tissue $[41,42]$. We further found significant relationship between PGRN and hs-CRP concentrations. A limitation of the present study is the small sample size evaluated. This is the first study evaluating and correlating hs-CRP and PGRN in CP with and without obesity and our data therefore suggest an association between CRP and PGRN levels and demonstrate that PGRN and hs CRP may be a biomarker of the chronic inflammatory response in obesity and CP thus justifying our hypothesis. This finding can be helpful in development of chair side kits for the rapid assessment of inflammatory status in periodontitis.

\section{Conclusion}

Thus within the limits of the current study, PGRN and hs-CRP levels may be markers of chronic inflammatory response in $\mathrm{CP}$ and obesity. Further longitudinal prospective studies involving a larger population are needed to confirm the findings of present study and to better understand the role of these markers in the pathogenesis, and also address the clinical implication and pathological mechanism of the markers in periodontal disease progression.

\section{Acknowledgement}

The authors acknowledge Mr. Manjunath Sharma, Statistician, Bangalore, India, for preparing the statistics. The authors report no potential conflict of interests.

\section{References}

[1] Kinane DF, Attstrom R. Advances in the pathogenesis of periodontitis. Group B consensus report of the fifth European Workshop in Periodontology, J Clin Periodontol 32 (2005), 130-131.

[2] Seidell JC. Obesity, insulin resistance and diabetes-a worldwide epidemic. Br J Nutr 83 (2000), 5-8.

[3] Must A, Spadano J, Coakley EH, Field AE, Colditz G, Dietz WH. The disease burden associated with overweight and obesity, J Am Med Assoc 282 (1999), 1523-29. 
[4] Ezzati M, Lopez AD, Rodgers A, Vander Hoorn S, Murray CJ. Comparative Risk Assessment Collaborating Group, Selected major risk factors and global and regional burden of disease, Lancet 360 (2002), 1347-60.

[5] Saito T, Shimazaki Y, Kiyohara Y et al. Relationship between obesity, glucose tolerance, and periodontal disease in Japanese women: The Hisayama study, J Periodontal Res 40 (2005), 346-53.

[6] Genco RJ, Grossi SG, Ho A, Nishimura F, Murayama Y. A proposed model linking inflammation to obesity, diabetes, and periodontal infections, J Periodontol 76 (2005), 2075-84.

[7] Dalla Vecchia CF, Susin C, Rösing CK, Oppermann RV, Albandar JM. Overweight and obesity as risk indicators for periodontitis in adults, J Periodontol 76 (2005), 1721-8.

[8] Nishida N, Tanaka M, Hayashi N et al. Determination of smoking and obesity as periodontitis risks using the classification and regression tree method, $J$ Periodontol 76 (2005), 923-8.

[9] Bateman A, Bennett HP. Granulins: The structure and function of an emerging family of growth factors, $J$ Endocrinol $\mathbf{1 5 8}$ (1998), 145-51.

[10] Daniel R, Daniels E, He Z, Bateman A. Progranulin (acrogranin/PC cell-derived growth factor/granulin-epithelin precursor) is expressed in the placenta, epidermis, microvasculature, and brain during murine development, Dev Dyn 227 (2003), 593-9.

[11] He Z, Bateman A. Progranulin (granulin-epithelin precursor, PC-cell-derived growth factor, acrogranin) mediates tissue repair and tumorigenesis, $J$ Mol Med 81 (2003), 600-12.

[12] Parnell PG, Wunderlich J, Carter B, Halper J. Transforming growth factor e: Amino acid analysis and partial amino acid sequence, Growth Factors 7 (1992), 65-72.

[13] Gijselinck I, van der Zee J, Engelborghs S et al. Progranulin locus deletion in frontotemporal dementia, Hum Mutat 9 (2008), 53-8.

[14] Bhandari V, Giaid A, Bateman A. The complementary deoxyribonucleic acid sequence, tissue distribution, and cellular localization of the rat granulin precursor, Endocrinology 133 (1993), 2682-2689.

[15] Daniel R, He Z, Carmichael KP, Halper J, Bateman A. Cellular localization of gene expression for progranulin, $\mathrm{J}$ Histochem Cytochem 48 (2000), 999-1009.

[16] Serrero G, Ioffe OB. Expression of PC-cell-derived growth factor in benign and malignant human breast epithelium, Hum Pathol 34 (2003), 1148-54.

[17] Zanocco-Marani T, Bateman A, Romano G, Valentinis B, He $\mathrm{ZH}$, Baserga R. Biological activities and signaling pathways of the granulin/epithelin precursor, Cancer Res 59 (1999), 5331-40.

[18] Zhu J, Nathan C, Jin Wet al. Conversion of proepithelin to epithelins: Roles of SLPI and elastase in host defense and wound repair, Cell 111 (2002), 867-878.

[19] He Z, Ong CH, Halper J, Bateman A. Progranulin is a mediator of the wound response, Nat Med 9 (2003), 225-29.

[20] Youn BS, Bang SI, Klöting N et al. Serum progranulin concentrations may be associated with macrophage infiltration into omental adipose tissue, Diabetes 58 (2009), 627-36.

[21] Ebersole JL, Cappelli D. Acute-Phase reactants in infections and inflammatory diseases, Periodontol 200023 (2000), 1949.

[22] Oberbach A, Tonjes A, Kloting $\mathrm{N}$ et al. Effect of a 4 week physical training program on plasma concentrations of inflammatory markers in patients with abnormal glucose tolerance,
Eur J Endocrinol 154 (2006), 577-85.

[23] Esposito K. Giugliano D: The metabolic syndrome and inflammation: association or causation, Nutr Metab Cardiovasc Dis 14 (2004), 228-32.

[24] Noack B, Genco RJ, Trevisan M, Grossi S, Zambon JJ, De Nardin E. Periodontal infections contribute to elevated systemic C-reactive protein level, J Periodontol 72 (2001), 121127.

[25] Craig RG, Yip JK, So MK, Boylan RJ, Socransky SS, Haffajee AD. Relationship of destructive periodontal disease to the acute-phase response, J Periodontol 74 (2003), 1007-16.

[26] Al-Zahrani MS, Alghamdi HS.Saudi. Effect of periodontal treatment on serum C-reactive protein level in obese and normal-weight women affected with chronic periodontitis, Med J 33 (2012), 309-14.

[27] Ekuni D, Tomofuji T, Irie K et al. Effects of periodontitis on aortic insulin resistance in an obese rat model, Lab Invest 90 (2010), 348-59.

[28] Loe $\mathrm{H}$. The gingival index, the plaque index and the retention index system, J Periodontol 38 (1967), 610-16.

[29] Glavind L, Loe. H. Errors in the clinical assessment of periodontal destruction, J Periodontal Res 2 (1967), 180-84.

[30] World Health Organization. The Asia-Pacific perspective. Redefining obesity and its treatment International Diabetes Institute February 2000.

[31] Loe H, Holm-Pedersen P. Absence and presence of fluid from normal and inflamed gingivae, Periodontics 3 (1965), 171-7.

[32] Ravishankaran P, Karunanithi R. Clinical significance of preoperative serum interleukin 6 and C-reactive protein level in breast cancer patients, World J Surg Oncol 9 (2011), 18.

[33] Kanaparthy R, Kanaparthy A, Mahendra M. C-reactive protein as a marker of periodontal disease, Gen Dent 60 (2012), 1-5.

[34] Amar S, Zhou Q, Dasthagirisaheb YS, Leeman S. Diet induced obesity in mice causes changes in immune responses and bone loss manifested by bacterial challenge, Proc Natl Acad Sci U $S$ A 104 (2007), 20466-71.

[35] Bruun JM, Lihn AS, Verdich C et al. Regulation of adiponectin by adipose tissue-derived cytokines: in vivo and in vitro investigations in humans, Am J Physiol Endocrinol Metab 285 (2003), 27-33

[36] Preshaw PM, Foster N, Taylor JJ. Cross-susceptibility between periodontal disease and type 2 diabetes mellitus: An immunobiological perspective, Periodontol 200045 (2007), 138-57.

[37] Pitiphat W, Savetsilp W, Wara-Aswapati N. C-reactive protein associated with periodontitis in a Thai population, $J$ Clin Periodontol 35 (2008), 120-5.

[38] Eriksen JL, Mackenzie IR. Progranulin: Normal function and role in neurodegeneration, J Neurochem 104 (2008), 287-297.

[39] Pradeep AR, Shiva Manjunath SRG, Kathariya R. Progressive periodontal disease has a simultaneous incremental elevation of gingival crevicular fluid and serum CRP levels, $J$ Investig Clin Dent 1 (2010), 133-8.

[40] Tüter G, Kurtis B, Serdar M. Evaluation of gingival crevicular fluid and serum levels of high-sensitivity C-reactive protein in chronic periodontitis patients with or without coronary artery disease, J Periodontol 78 (2007), 2319-24.

[41] Lu Q, Jin L. Human gingiva is another site of C-reactive protein formation, J Clin Periodontol 37 (2010), 789-96.

[42] Megson E, Fitzsimmons T, Dharmapatni K, Bartold PM. Creactive protein in gingival crevicular fluid may be indicative of systemic inflammation, J Clin Periodontol 37 (2010), 797804. 


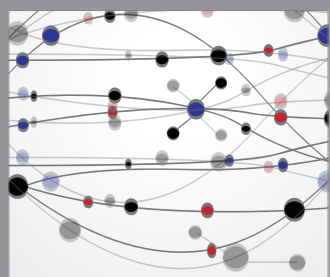

The Scientific World Journal
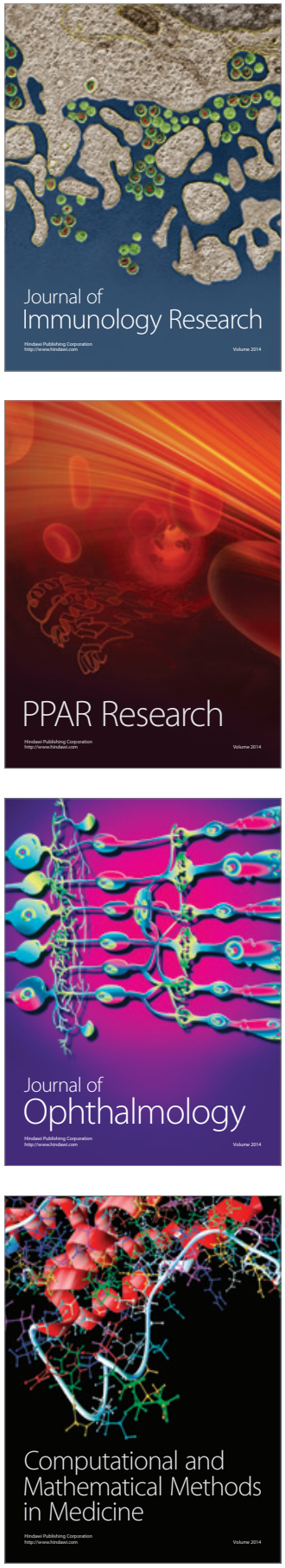

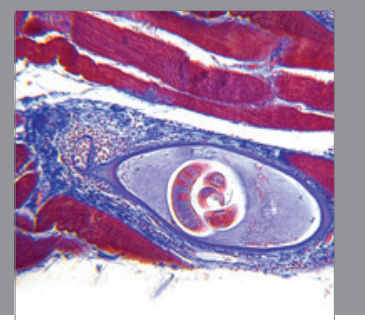

Gastroenterology

Research and Practice
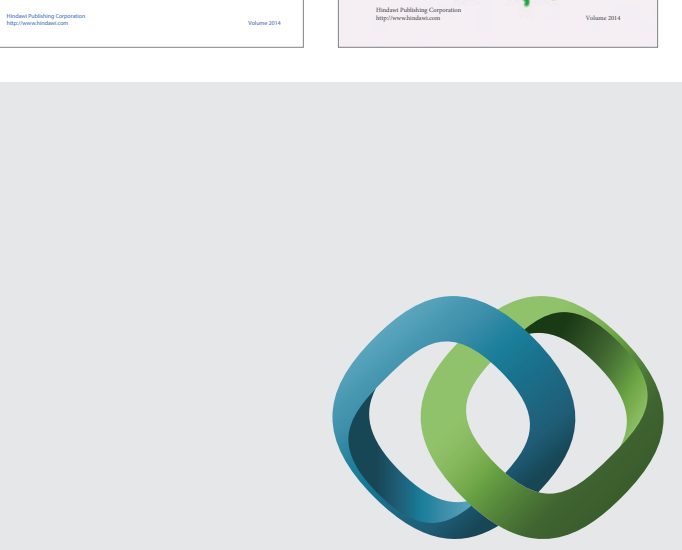

\section{Hindawi}

Submit your manuscripts at

http://www.hindawi.com
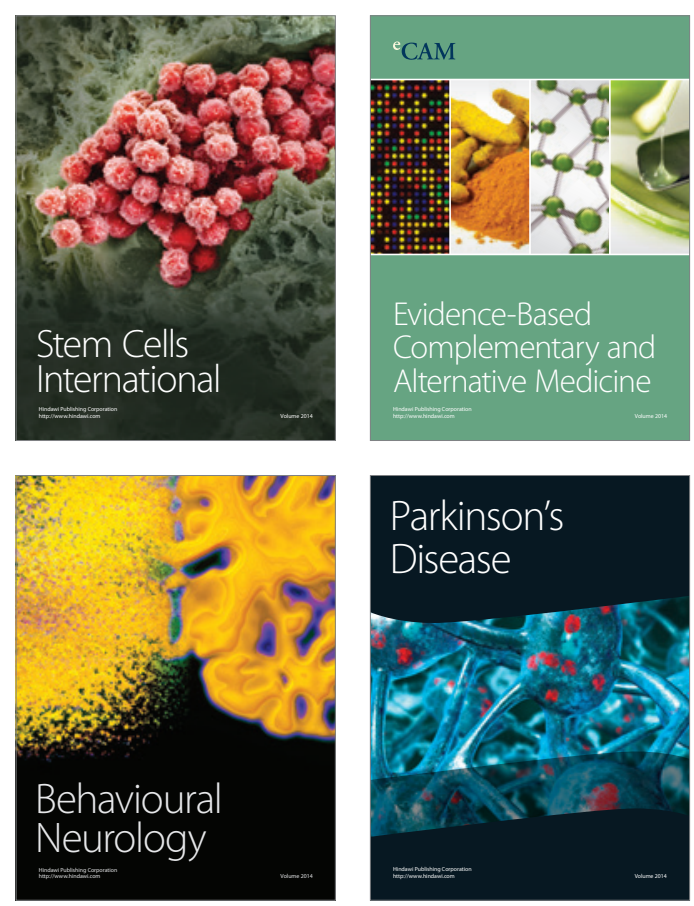

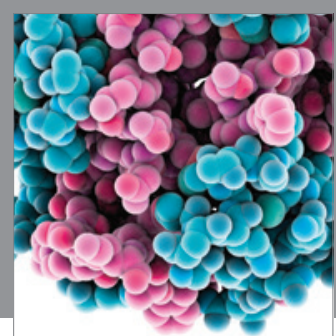

Journal of
Diabetes Research

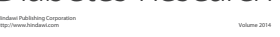

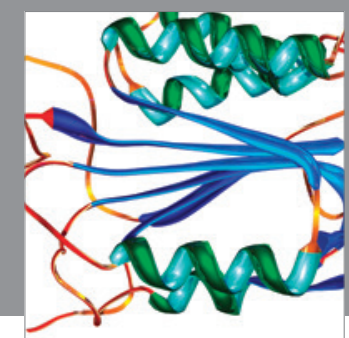

Disease Markers
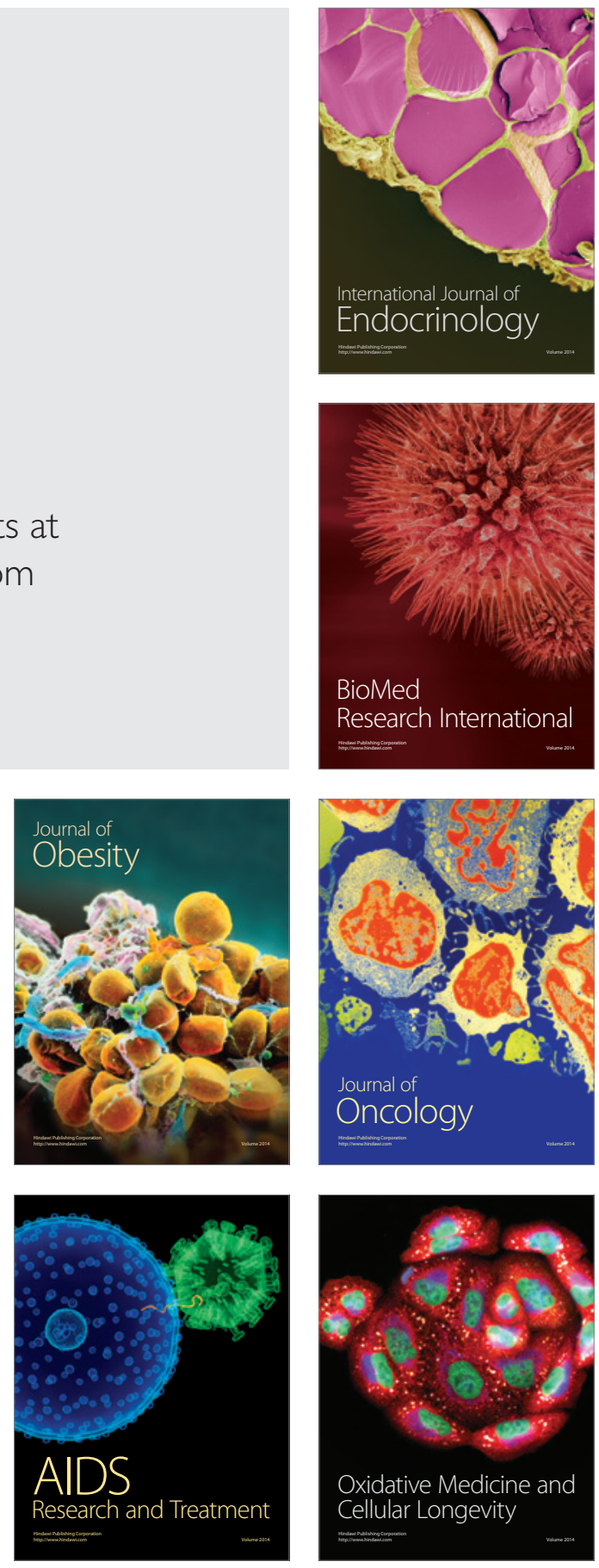